\title{
Core/periphery spatial interrelation in historic cities: Tripoli (Lebanon) as a case study
}

\author{
N. Mohareb \\ Faculty of Architectural Engineering, Beirut Arab University, Lebanon
}

\begin{abstract}
'Societies control the boundaries that they create' (Madanipour, Public and private spaces of the city, 2003). Throughout history, urban peripheries have evolved and been transformed, creating forms of distinction. Emphasising those peripheries affects those social relationships that take a spatial form and, overtime, will cause a changing social phenomenon. Although the periphery of historic cores is indeed a spatial separating edge, it is at the same time the threshold that leads to the outside realm through the edges' spatial and visual connectivity. Prior to any regeneration interventions, it is crucial to understand the current situation of the historic core, in addition to analysing the core/periphery interrelation. This spatial interrelation analysis would contribute effectively to the decision-making related to sustainable regeneration projects and the prosperity of the historic core that increases the liveability of our cities.

The current usage of spatial configuration is limited to either analysing the core of the city or examining its outer urban growth, while studying the edge itself, between the historic core and the outer urban growth, is ignored. This paper aims to investigate the core/periphery interrelation based on their spatial configuration in historic cities, with a special reference to Tripoli (Northern Lebanon) as a case study. The paper develops an appropriate framework to analyse that interrelationship.

This analysis will verify whether the urban historic periphery acts as a barrier in its various conditions, and examines its mutual effects on both sides of the periphery that might affect the 'liveability' of the historic core of Tripoli city. Keywords: core/periphery interrelation, historic core, urban historic edges.
\end{abstract}




\section{Introduction}

Throughout history, the city's peripheries have evolved and transformed, creating forms of distinction. Emphasising those boundaries affects the social relationships that take a spatial form and over time will cause a changing social phenomenon [1]. Although the periphery is indeed a separating edge, it is at the same time the threshold that leads to the outside realm through its accessible entry points. On examining the urban periphery of a historic city, they can be seen to have become different from their original formatting as, today, they appear to be more complex and situated between historic core centres and their adjacent urban growth. Governa and Saccomani [2] view the periphery from two main perspectives: spatial characteristics and the socioeconomic point of view. First, the existing polycentric urban settlements on the periphery are the consequence of weakening the spatial hierarchy of the city at its periphery along with the recent dynamic changes that are represented by the diffusion process of settlements. Second, globalisation affects the territorial organisation of the periphery, causing a social exclusion and loss of cohesion that consequently affects both the urban regeneration plans inside the historic core and the modern patterns and styles outside the historic core [2]. Some studies refer to the urban periphery as 'neighbourhoods in crisis' due to the neglect of planning and poor management of their urban fringe in a way that Jed Griffiths (1994) describes as 'planning's last frontier' [3]. On the other hand, an Italian experience, in the city of Turin, shows that the urban periphery should be an integrated part of the city rather than a problematic segregated frontier.

Defining a periphery is actually defining a space's identity on both its levels: its enclosure and its exposure to the outside realm in addition to its interrelation with the historic core. This paper adopts Madanipour's (2003) and Conzen's main considerations [4] as a framework for studying the urban peripheries (see table 1).

Many aspects interrelate the historic core with its periphery, such as the political, socioeconomic, architectural, cultural, spatial, and others. This paper considers the spatial aspect as a base factor, which can quantitatively measure the chronological transformation of the core/periphery interrelation until the current situation. The spatial configuration analysis adopts Hillier's theory of space syntax $[5,6]$, in conjunction with Martin's examination of the block size and its effect on both the space and its inhabitants [7], and Bosselmann's temporal factors of movement experience $[8,9]$. The paper will use each theory in combination to form the spatial configuration part of the framework.

Tripoli, which is located on the northern side of Lebanon, is selected as a case study. The historic core is still active and maintains mostly its architectural character. It includes the main suqs, religion buildings, and trading facilities in addition to the residential quarters. Number of reviving intervention projects were executed in the historic core, some of them were successfully accomplished such as the rehabilitation of Souk al-Sagha (Jewellers' market) and Khan alKhayyatin (Tailors' Caravanserai), while other reviving projects were stumbled as various mosques, hammams (traditional Turkish bath). Most of these projects 
depend on resorting a single building rather than considering the historic core as one unit. The previous points are the main reason for choosing this city, as most of the intervention neither changed the cultural sense of the place nor transformed it into a museum such as what was done, for an example, in Medina in Malta.

Table 1: $\quad$ Highlights the paper's framework that is based on both Madnipour and Conzen questions (source: author).

\begin{tabular}{|c|c|}
\hline $\begin{array}{l}\text { Understanding historic urban } \\
\text { periphery }\end{array}$ & Research points \\
\hline $\begin{array}{l}\text { - How they are constructed } \\
\text { - Formation stage } \\
\text { - Modification stage }\end{array}$ & $\begin{array}{l}\text { - The historic background } \\
\text { - The construction era and its effect } \\
\text { - Spatial transformation of the } \\
\text { periphery through time }\end{array}$ \\
\hline - What they are made of & $\begin{array}{l}\text { - The spatial configuration typology } \\
\text { - Architectural features } \\
\text { - Land use types on the edge }\end{array}$ \\
\hline $\begin{array}{l}\text { - What they are meant to signify and } \\
\text { the reason for their construction }\end{array}$ & $\begin{array}{l}\text { - The edge's value at the time of } \\
\text { construction } \\
\text { - Current existence value (tangible } \\
\text { and intangible value) }\end{array}$ \\
\hline $\begin{array}{l}\text { The interrelationship between the core } \\
\text { and the periphery, studying the edge } \\
\text { effect }\end{array}$ & $\begin{array}{l}\text { - Examining the buffer zone on both } \\
\text { sides of the periphery } \\
\text { - Examining the periphery itself } \\
\text { - Investigating the relationship of } \\
\text { both sides of the edge } \\
\text { - Connectivity } \\
\text {-Architectural style } \\
\text { - Land uses types and locations }\end{array}$ \\
\hline
\end{tabular}

\section{Investigating the core/periphery interrelation of Tripoli}

Tripoli (Lebanon) is not the only Arab city with the name of Tripoli, as there is also a Tripoli in Libya; however, this city is distinguished as 'Tarabulus alSham' or 'Tripoli of the West' [10]. It is the second largest city after Beirut, located on the north coast of Lebanon. 'Tripolis' or the 'Tri-city' was three cities merged together [11]. The Greek name came from the series of independent citystates established due to the geographic conditions - Tyrian, Sidonian and Aradian - although these cities are no longer in existence. In 1289, Mamluk Sultan Al-Mansur Qalawun abandoned the old city on the harbour, which is currently known as El-Mina [10]. He built a new city on the Pilgrims' Hill about three kilometres inland, which is the origin of the present historic core of Tripoli city. From the fourteenth to the end of the nineteenth centuries, Tripoli consisted of what are now the old parts of El-Mina and the old city. For a long period of the city's history, it was attached to Damascus; however, the British conquered 
the region in 1918, and Tripoli became part of Lebanon in 1920. The old part of the city around the harbour (El-Mina) contains the remains of fortified towers and walls. The old city had no fortifications, but was characterised by compact urban forms, narrow and winding streets, and gates at some parts of its inner neighbourhoods. The locations of the cemeteries when compared to older maps indicate that the outer limits of the city were almost the same as those of what now defines the Old City core [12] (see fig. 2). The area between El-Mina and the old city is heavily constructed with new architectural styles and modern urban fabric (see figs 1 and 2).

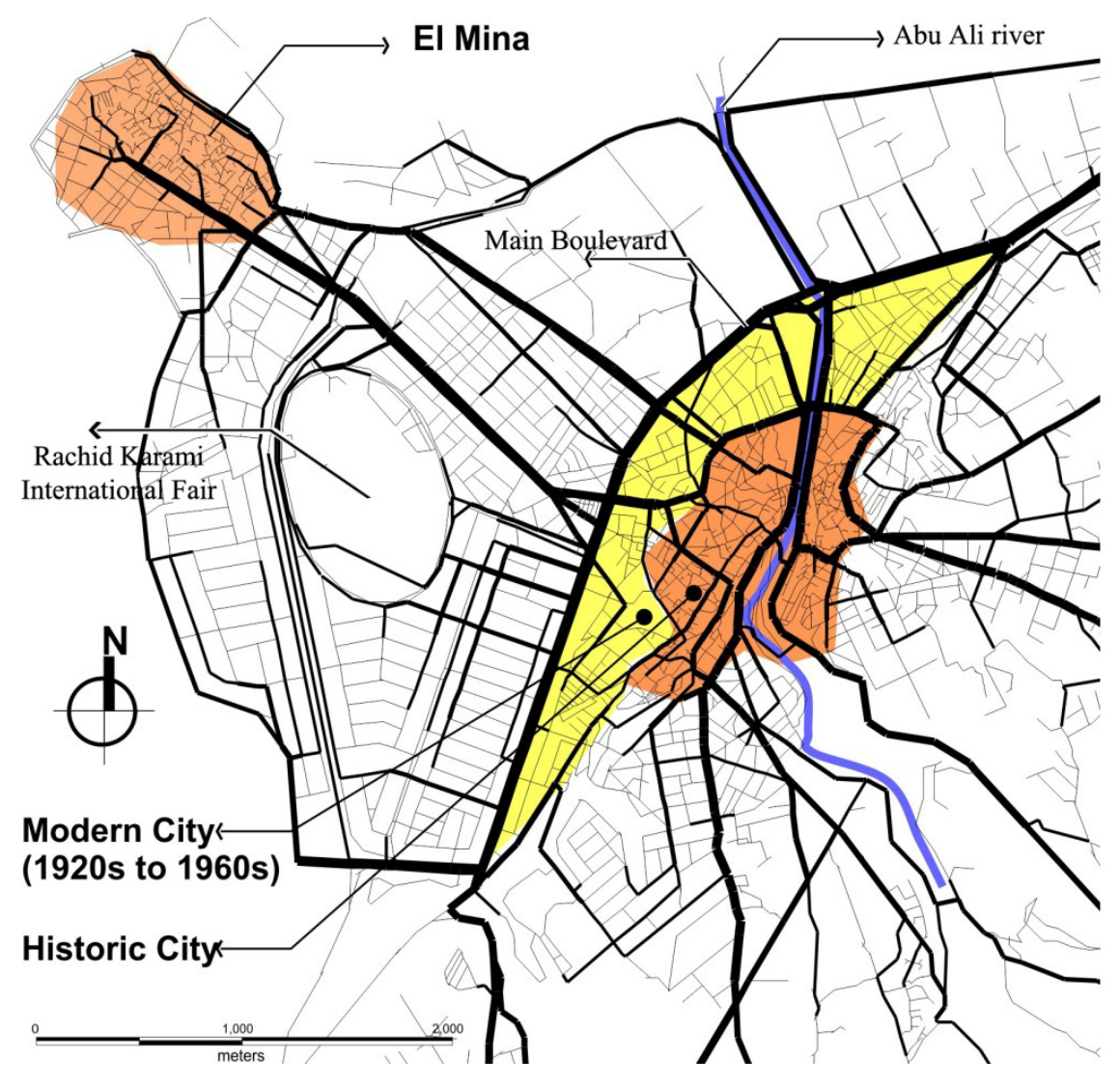

Figure 1: Illustrates the main routes that have high accessible potential movement (through-movement). The thick lines in the figures indicate high accessible routes than the thinner lines. In addition, the figure shows both historic and the modern city (Old Tripoli and El Mina) (source: author). 
Three cycles of urban growth have affected Tripoli. The first cycle was inside the historical core in old Tripoli and El-Mina, and the second cycle was from the 1920 s to the 1960s, as the urban growth extended along the connection between the old city and El-Mina while the growth was slower on the boulevard that connects the city from Beirut to Syria (see fig. 2). At the edge of the old city, a number of schools were built; the wholesale vegetable market at Bab El Tibbana also expanded. Moreover, a number of warehouses settled on the periphery of the new urban growth at Bahsas, outside the southern edge of the city. However, in the third growth cycle, the situation was reversed, as the boulevard attracted the main growth across the city and a new residential neighbourhood was constructed towards the main city entrance from the southern part. In El-Mina sector, the eastern part represents the historic fabric with its old architectural style of cross-vaults. Due to the nature of the historic site of El-Mina sector, which is surrounded by water from three sides, the urban growth was limited to the southern part and the extension to the main historic core. The southern part of El-Mina started to expand around the 1940s.

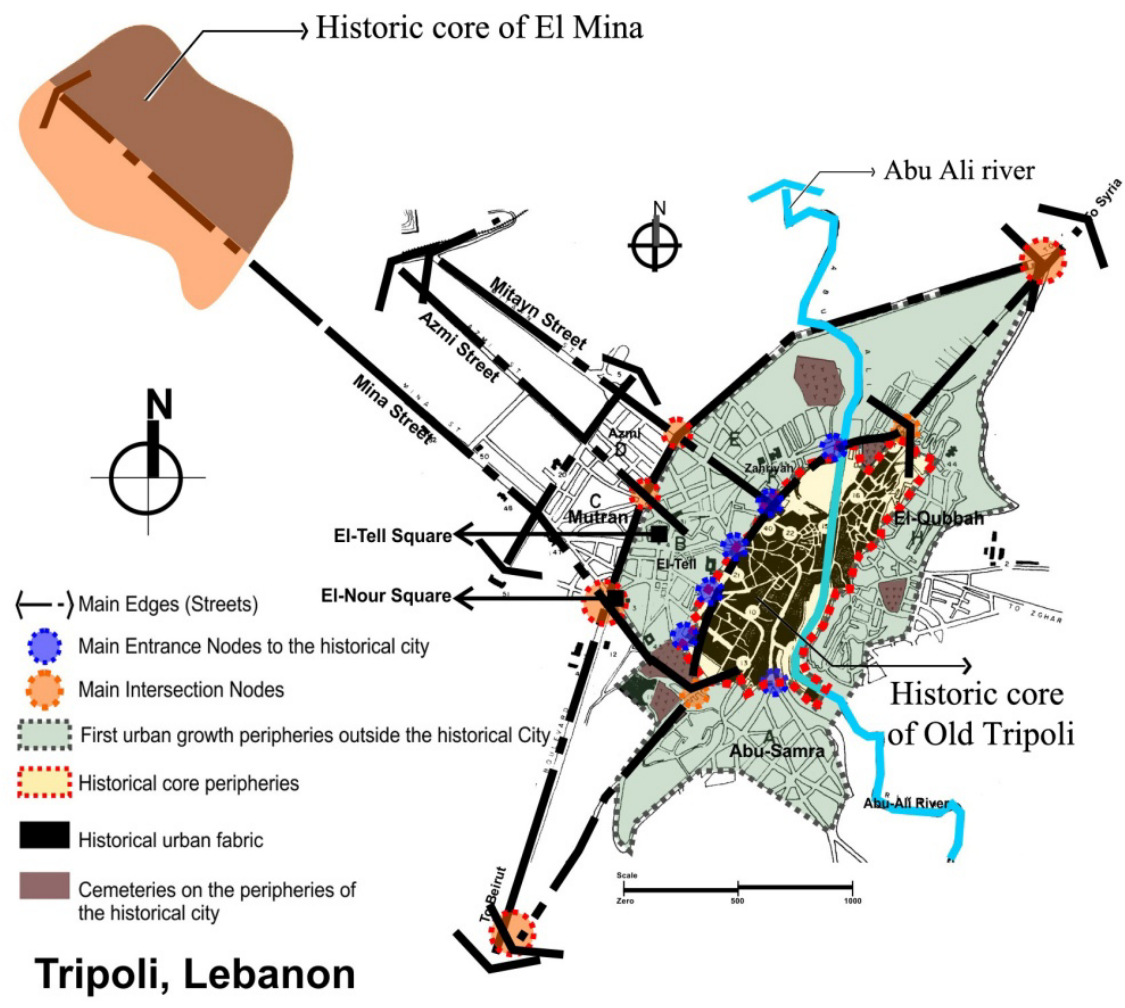

Figure 2: Shows the historic core and the spatial relationship with the surrounding context including the main entry points and the main connecting routes from 1961 until the present. 
In this spatial study of Tripoli, both the first and the second waves of urban growth are included as one unit, while the boulevard acts as the urban edge. On the other side of the city, on the edge of El-Mina is the Ibn Khaldoun route towards the south, and the El-Mina route to the west.

Despite the differences in architectural styles and urban fabric patterns, which reflects a clear edge between the two fabrics, historic Tripoli is still highly connected with the second wave of urban growth, see fig. 3 . The connections are an extension of commercial routes from inside the historic city towards the outside. In contrast, the El-Mina Street acts as a physical barrier that conceals both the historic fabric and the historic architectural style; see fig. 1 for the spatial configuration segregation. The land use of this part of the historic city of El-Mina is mainly residential in its core and partially commercial at its northern waterfront; therefore, the pedestrian movements are highly accessible, while the vehicle movement is segregated from the inner part of the historic fabric.

The main boulevard seems to be a physical boundary between the historic city and the El-Mina sector, which separates not only the spatial fabrics but also architectural styles. However, there are three main routes - Mina St., Azmi St., and Mitan St. - that act as a perpendicular connector, where two of them start from the inside of the historic core. The three routes increase the accessibility between the successive layers of urban growth and the historic fabric. In addition, they also articulate the smooth transition of architectural style along their sides, from the historic features to the postmodern ones located at El-Mina.

The historic core has severe traffic jams, due to a number of problems. First, the governmental buildings are still concentrated either inside the historic core or along the boulevard with fewer parking facilities. Also, there are fewer variations regarding the public transportation facilities, which increases the usage demands of private cars, in addition to a lot of light traffic along the boulevard, which slows down the traffic and has two contrary effects. On the one hand, slowing down the vehicle traffic on the boulevard increases the travelling time to the required destinations and increases different types of pollution, such as visual, sound and environmental pollution. On the other hand, it increases pedestrian movement as shown in the current situation of fig. 3, as the through-movements and to-movements on $\mathrm{R} 500 \mathrm{~m}$ increase more on the three main stops on the boulevard. The spatial presentation in fig. 3 highlights the accessible routes (darker lines indicate higher values while lighter lines show lower measurements), which is a typical presentation of space syntax thematic maps, extracted from the calculation of juxtaposition routes' relationship.

As a result, the historical core is still active and has higher pedestrian movements compared to the other parts of the city. In the El-Mina sector, the traffic jams are far less than in the historic core of the city, due to the nature of its land-use distributions and the organic spatial configuration. The land uses along the urban edge are mostly commercial on the ground floor and governmental facilities and they are located on the highest accessibility routes. The residential usages are located towards the inside on both sides of the urban edges. Buildings are also higher outside the historic core, and the highest parts 
Tripoli in 1945

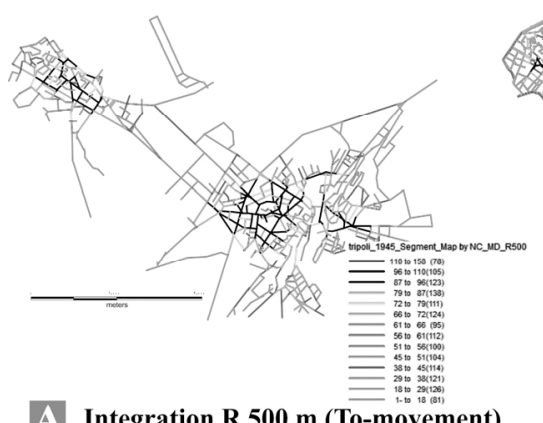

\section{Tripoli at present}
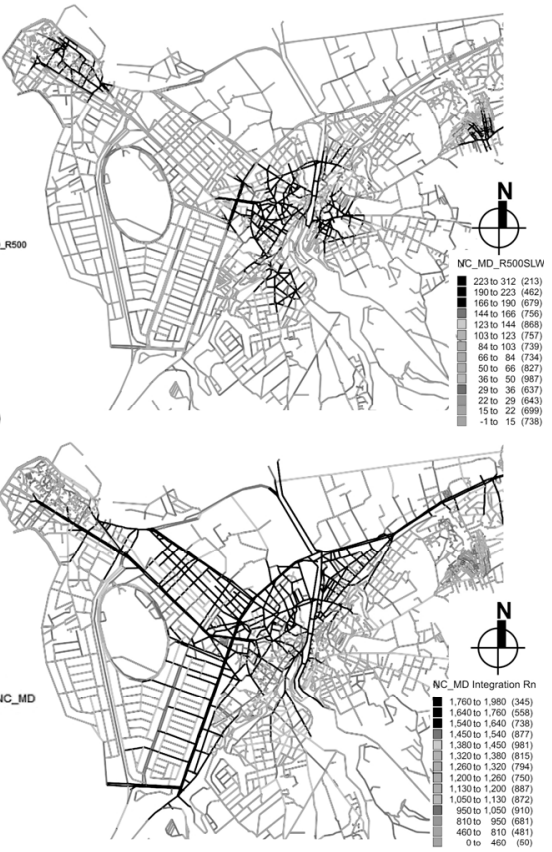

B Integration RN (To-movement)

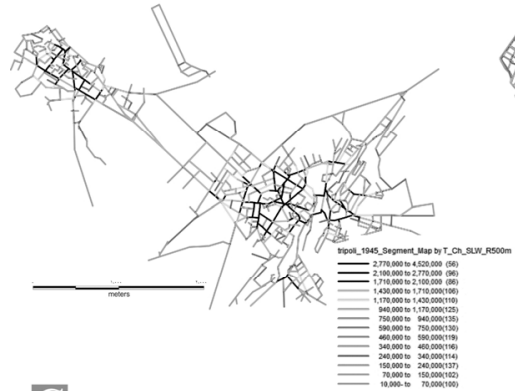

Choice R 500 m (Through-movement)
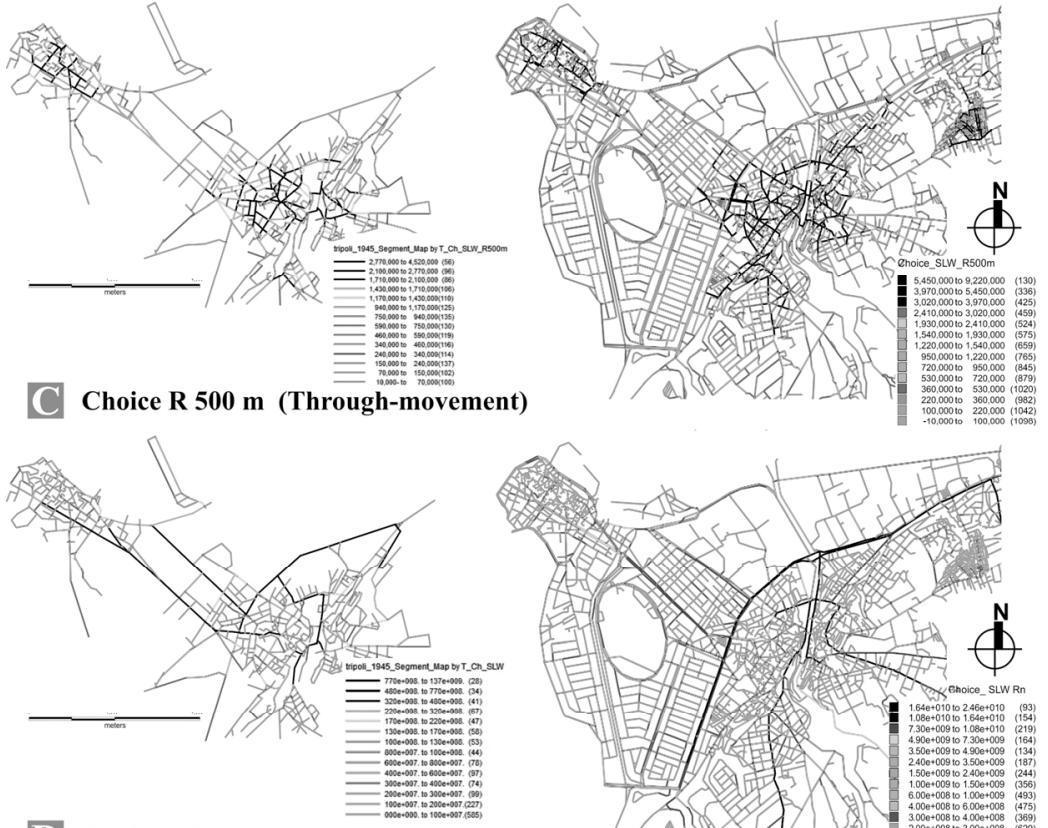

D Choice RN (Through-movement)

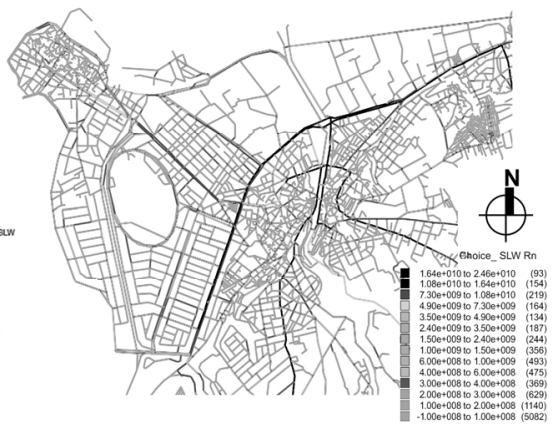

Figure 3: Spatial transformation of Tripoli in 1945 and present (source: author). 
are located in the new districts such as El Dume W-Elfarz (acquisition and sorting district) (12 floors in height).

Through time, it would be expected that the spatial configuration outside the urban edges would alter the accessibility conditions and route usage along that urban edge; however, this has not been the case in Tripoli. Analysing the spatial configuration of the two eras - 1945 and the present situation - it is clear from fig. 3 that the urban edges maintained their spatial configuration on both the pedestrian and vehicle levels, except in the southern part, as it includes the new residential extensions that were constructed recently. Throughout the last 70 years, still the historical core has remained active and alive, and has not been affected by the urban growth cycles. On the contrary, in the El-Mina sector, the urban edges act as a spatial and architectural style barrier, which minimises the interaction between the historic part of El-Mina and the surrounding context.

Emphasising on this idea, a further cognitive exercise was given to number of students studying at the BAU University in Tripoli to replicate a 50 year experiment done by John Gulick on students from Tripoli studying at AUB University to explore the cognitive image of the city using Kevin Lynch approach [12]. It was astonishing that the key landmarks sketched by the current study almost resembled the prior study by Gulick. The students select and draw almost the same buildings and places, main important routes and paths that, from their point of view, represent the important current features. This result means that the past 50 years of development and urban growth beyond the traditional city core did not change the cognitive image of the city to its inhabitant, and the periphery of the historic core; the boulevard acted as a connector rather than a separator between the historic core and the extended urban growth of the city.

\section{Conclusion}

Although the limited economic growth of Tripoli city and the lack of new modern facilities such as mega malls or retails have a negative impact on the city's development in general; however, it kept the historic core alive. It still maintains its role in providing the majority of shopping, retails, workshops, light industry facilities for medium and lower income inhabitants. Despite the fact that the historic core is not visually accessible; the spatial accessibility has a major role to strengthen that connection and it provides the historic core, in particular the commercial sector, with the essential accessible entry points that keeps it alive and well functioning. In addition, the architectural features have a smooth transitional character from one era to another within the two layers of urban growth, which affects positively on the sense of place of the core and its periphery.

Any regeneration projects inside Tripoli historic core need to consider the interrelation with the surrounding context and provide the necessary connection with the historic periphery. This interrelation in this case study or other relevant cases would maintain the continuous usage and the successfulness of these intervention projects. They need to be accessible from the modern city that can facilitate essential needs such as transportation, parking, and other integrated 
services, in other words, to keep the inner historical core alive with continued appropriate usage.

Whilst this study is limited to Tripoli as a case study; however, it highlights the essential role of the periphery of the historic core that is connecting two different spatial characters: the historic fabric and the new extended fabric. Further investigating studies are needed to explore various methods of connections and how to improve that interrelation.

\section{References}

[1] Madanipour, A., Public and private spaces of the city, Taylor \& Francis, 2003.

[2] Governa, F. \& Saccomani, S., From urban renewal to local development. New conceptions and governance practices in the Italian peripheries, Planning Theory and Practice 5(3), pp. 327-348, 2004.

[3] Gallent, N., Shoard, M., Andersson, J., Oades, R. \& Tudor, C., England's urban fringes: Multi-functionality and planning. Local Environment, 9(3), pp. 217-233, 2004.

[4] Conzen, M. P., How cities internalize their former urban fringes: A crosscultural comparison, Urban Morphology, 13(1), pp. 29-54, 2009.

[5] Hillier, B. \& Hanson, J., Social logic of space, Cambridge University Press, Cambridge, 1984.

[6] Hillier, B., Turner, A., Yang, T. \& Park, H.-T., Metric and topo-geometric properties of urban street networks: Some convergences, divergences and new results, 6th International Space Syntax Symposium, Istanbul, 2007.

[7] Carmona, M., Heath, T., Oc, T. \& Tiesdell, S., Public places urban places: The dimensions of urban design, Architectural Press, Oxford, 2006.

[8] Bosselmann, P., Representation of places: Reality and realism in city design, University of California Press, 1998.

[9] Bosselmann, P., Urban transformation: Understanding city design and form, Island Press, Washington DC, 2008.

[10] Bosworth, C. E. (eds). Historic cities of the Islamic world, Brill, Leiden Boston, 2007.

[11] Jidejian, N., Tripoli through the ages, Librairie Orientale, 1980.

[12] Gulick, J., Images of an Arab city. Journal of the American Planning Association, 29(3), pp. 179-198, 1963. 